Revista Complutense de Educación

ISSNe: 1988-2793

http://dx.doi.org/10.5209/RCED.58893

\title{
Análisis del Impacto de los Programas de Mejora de la Calidad Educativa en Centros Escolares Públicos
}

Autores: Laura López-Torres, Diego Prior y Daniel Santín

Editorial: Centro de Estudios Ramón Areces

Año de publicación: 2017

$N^{\circ}$ de páginas: 48

ISBN: 978-84-617-6745-8

Los autores de este libro monográfico, Laura López-Torres, Diego Prior y Daniel Santín, están afiliados a departamentos de empresa o de economía aplicada en las universidades Autónoma de Barcelona y Complutense de Madrid.

El libro se desarrolla como un estudio monográfico hecho por economistas con el objetivo de aportar evidencias, basadas en investigación, sobre algunos aspectos concretos del sistema educativo escolar español.

El trabajo ha sido auspiciado por la Fundación Ramón Areces y la Fundación Europea Sociedad y Educación. Estas fundaciones publican anualmente este tipo de estudios de los que el presente es una muestra más.

Los autores explican que el gasto en educación es una inversión con retorno ya que potencia la formación intelectual, mejora el capital humano y permite aumentar las tasas de crecimiento de un país.

Los datos del estudio se refieren a un panel que cubre aproximadamente el $80 \%$ de los centros públicos escolares de Educación Primaria en Cataluña. El título del libro es por tanto mucho más ambicioso que lo que en realidad se hace en sus contenidos. Los autores del libro sostienen que el panel de datos es equilibrado, pero estadísticamente este concepto "equilibrado" no ha sido tratado para la selección de una muestra real en un marco poblacional como el que se dispone.

Como aluden a un término que no es claro, es posible que su intención fuese decir que los datos de panel eran "representativos", pero no basta con decir el adjetivo sino explicar además qué proporciones poblacionales se respetan en la muestra y cómo se obtiene la muestra con dichas proporciones.

Por ejemplo, el $80 \%$ de los centros escolares se refiere a que los centros escolares investigados se limita a un $80 \%$ del total y elegidos por criterios de conveniencia del investigador. En tal caso habría una proporción del 20\% de no respuesta que debería ser tratada para no acarrear sesgos en las estimaciones posteriores. O bien significa que el $80 \%$ de los centros estudiados fueron elegidos aleatoriamente con unas probabilidades predeterminadas de selección. Todo esto no queda aclarado y sería necesario aclararlo para hacer un análisis claro y objetivo. Estos porcentajes deberían ser usados en las metodologías estadísticas, pero no se hace en el libro. De hecho parece que la investigación hubiera sido prácticamente semejante si se hubieran observado un $50 \%$, un $5 \%$ o un $1 \%$ de los centros escolares referidos. 
El estudio econométrico, en todo caso y por los modelos planteados en el libro, es de unos modelos subjetivos (podrían ser perfectamente otros los modelos econométricos usados) y aunque sirven de investigación o de análisis éstos no serían objetivos. Un ejemplo es que no se puede garantizar la insesgación de las estimaciones, algo que sería de justicia hacer. La idea que subyace es más ideológica o técnológica que plenamente científica, por lo que la calidad científica del libro es muy limitada. Algunas referencias relativamente recientes que han tratado el problema de no respuesta en encuestas, además del artículo pionero de Hansen y Hurwitz (1946), son los de Ruiz Espejo (2011, 2015, 2017) y Thompson (2012).

Hay un problema de fondo, que consiste en utilizar técnicas econométricas que podrían tener sentido con variables económicas, y aplicarlas a poblaciones humanas porque los datos son de escolares. El uso frecuente en economía de tener ciertas ideas preconcebidas y que se reflejen en los modelos que se estudian, no parece ser el camino más idóneo para tratar los datos de personas y su evaluación.

La pretensión de orientar al legislador puede ser informativa con sesgos y a mi modo de ver no puede ser vinculante por la subjetividad en los métodos empleados.

\section{Referencias bibliográficas}

Hansen, M. H. \& Hurwitz, W. N. (1946). The problem of nonresponse in sample surveys. Journal of the American Statistical Association, 41, 517-529.

Ruiz Espejo, M. (2011). An objective solution to the problem of unbiased estimation with nonresponse. Statistical Reports, 13, 1-2.

Ruiz Espejo, M. (2015). Estimación insesgada objetiva para no respuesta. Estadística Española, 57, 29-37.

Ruiz Espejo, M. (2017). Ciencia del Muestreo. Madrid: Bubok.

Thompson, S. K. (2012). Sampling, Tercera edición. Hoboken, NJ: Wiley.

Mariano Ruiz Espejo
ruizesp@gmail.com

Universidad Católica San Antonio de Murcia 